\title{
Relationship between Classic Physiological Variables and Running Performance in Recreational Runners
}

\author{
Fuminori Takayama ${ }^{1,2}$, Atsushi Aoyagi $^{3}$ and Yoshiharu Nabekura1 \\ ${ }^{1}$ Faculty of Health and Sport Sciences, University of Tsukuba 1-1-1 Tennodai, Tsukuba-shi, Ibaraki 305-8574, Japan \\ E-mail: fuminori.takayama1990@gmail.com \\ ${ }^{2}$ Research Fellow of Japan Society for the Promotion of Science 5-3-1 Kojimachi, Chiyoda-ku, Tokyo 102-0083, Japan \\ ${ }^{3}$ Graduate School of Comprehensive Human Sciences, University of Tsukuba 1-1-1 Tennodai, Tsukuba-shi, Ibaraki \\ 305-8574, Japan \\ [Received July 4, 2017; Accepted March 28, 2018; Published online April 23, 2018]
}

\begin{abstract}
The purpose of this study was to investigate the relationship between classic physiological variables [maximal oxygen uptake $\left(\dot{\mathbf{V}} \mathbf{O}_{2}\right.$ max), \% $\dot{\mathbf{V}} \mathbf{O}_{2}$ max at anaerobic threshold (AT), and running economy (RE)] and running performance in recreational runners. 39 recreational runners (24 males and 15 females) underwent a treadmill running test to determine the classic physiological variables and velocity at AT (vAT). AT was defined as the point at which the respiratory exchange ratio stabilized above 1.0, and it was used as an indirect performance variable. Multiple regression analysis showed that $94 \%$ of vAT values were explained by all classic physiological variables $(\mathrm{p}<0.001)$. In addition, all variables were significantly explanatory $\left(\dot{\mathbf{V}} \mathbf{O}_{2} \max , p<\right.$ $0.001 ; \% \dot{\mathbf{V}} \mathrm{O}_{2}$ max at AT, $\mathrm{p}<0.001$; and $\left.\mathrm{RE}, \mathrm{p}<0.001\right)$. In total, 35 subjects had completed a marathon within the past year. For these subjects, single regression analysis was performed, which showed that $67 \%$ of recent marathon times was explained by vAT $(r=0.82, p<0.05)$. This study indicated that during a treadmill running test, $\dot{\mathbf{V}} \mathrm{O}_{2} \max , \% \dot{\mathbf{V}} \mathbf{O}_{2}$ max at AT, and RE can precisely explain vAT, which is highly correlated with recent marathon times.
\end{abstract}

Keywords: maximal oxygen uptake, running economy, fractional utilization, anaerobic threshold

\section{Introduction}

The maximal oxygen uptake ( $\left.\mathrm{V}_{2} \max \right)$, fractional utilization of $\dot{\mathrm{V}}_{2} \max$ at anaerobic threshold $\left(\% \dot{\mathrm{V}}_{2}\right.$ max at $\left.\mathrm{AT}\right)$, and running economy (RE) are physiological variables that determine distance running performance (Joyner, 1991). These 3 variables have been used in the classic model for predicting distance running performance in elite runners (Joyner, 1991; McLaughlin et al., 2010; Tjelta et al., 2012). For example, McLaughlin et al. (2010) have found that the classic physiological variables explain $95 \%$ of the variation in $16-\mathrm{km}$ running performances.

It is well known that $\dot{\mathrm{V}} \mathrm{O}_{2} \max , \% \dot{\mathrm{V}}_{2}$ max at AT, and $\mathrm{RE}$ are limited by different factors. $\mathrm{V}_{2}$ max is largely determined by the maximal cardiac output, whereas it has been suggested that peripheral factors such as muscle fiber composition and fat metabolism limit $\% \dot{\mathrm{VO}}_{2}$ max at AT (Joyner and Coyle, 2008). RE is a multifactorial variable, which reflects metabolic, cardiorespiratory, biomechanical, and neuromuscular characteristics (Barnes and Kilding, 2015). Considering the training principle of specificity, the assessment of all classic physiological variables is valuable for runners to understand their physiological strengths and weaknesses (i.e., trainability). Jones and Carter (2000) have emphasized that endurance training should be conducted on the basis of trainability, as concluded from a review of the effect of endurance training on physiological variables.

Measurement of the functional capacity during a treadmill running test has the advantage of evaluating performance without being affected by the environmental factors such as climate and terrain. Many studies have reported that velocity at AT (vAT) during the treadmill running test is one of the best predictors of distance running performance (Farrell et al., 1979; Noakes et al., 1990; Rhodes and McKenzie, 1984; Roecker et al., 1998; Sjödin and Jacobs, 1981). This result is not surprising because vAT integrates $\dot{\mathrm{V}} \mathrm{O}_{2} \max , \% \dot{\mathrm{V}}_{2} \max$ at $\mathrm{AT}$, and RE (Joyner, 1991; Tjelta et al., 2012). Further, 
during a recent study on elite runners, it was found that the classic physiological variables explain $89 \%$ of the variation in vAT (Tjelta et al., 2012).

Countless recreational runners train hard to improve their distance performance (García-Pinillos et al., 2017). At present, many laboratories and sports facilities have expired gas analyzers, and the treadmill running test may be more accessible to recreational runners. In the past, compared with $\dot{\mathrm{V}}_{2} \max$, RE had not been considered as an important physiological factor for determining distance running performance in recreational runners (Engeroff et al., 2016). Engeroff et al. (2016) recently investigated the relationship between RE and vAT in recreational runners, and reported that runners with superior RE had a higher vAT among the runners with equivalent $\dot{\mathrm{VO}}_{2} \max$. These data suggest that $\mathrm{RE}$ influence performance even in recreational runners. However, to our knowledge, no previous study has sought to elucidate the relationship between $\dot{\mathrm{V}}_{2}$ max, \% $\dot{\mathrm{V}}_{2}$ max at $\mathrm{AT}$, and RE and performance in recreational runners.

Given the characteristic of recreational runners, it is preferable that the test to measure classic physiological variables and vAT is less invasive and easy to quantify. It has been previously reported that AT, which is defined as a respiratory exchange ratio (RER) greater than 1.0 (RER1.0) in the maximal incremental test where velocity is increased every minute, allowed a fair estimation of the velocity at maximal lactate steady state (MLSS) (Leti et al., 2012) and was reproducible with a low intra-individual variability (Laplaud and Menier, 2003). The RER1.0 method has the advantage that it can be quantified without using invasive procedures (i.e., blood sampling), which would be particularly important for recreational runners. Moreover, unlike other ventilatory methods, the RER 1.0 method is easy to perform and does not require individual subject data slope-fitting techniques (Chin et al., 2010). Therefore, RER1.0 is a useful method for measuring distance performance in recreational runners. A recent study has indicated that there were significant relationships between vAT, which was quantified by the RER1.0 method, and recent marathon time in 11 recreational runners who completed the same race one week before the test (Takayama et al., 2017). In that study, however, the sample size was relatively small and the detailed relationship between classic physiological variables and performance was not reported (Takayama et al., 2017).

The purpose of the present study was to investigate the relationship between classic physiological variables and VAT in recreational runners. Based on the previous findings discussed above, we hypothesized that $\dot{\mathrm{V}}_{2} \max , \% \dot{\mathrm{V}} \mathrm{O}_{2}$ max at $\mathrm{AT}$, and $\mathrm{RE}$ can precisely explain $\mathrm{vAT}$.

\section{Methods}

\subsection{Subjects}

39 recreational runners (24 males and 15 females) participated in the present study. Descriptive characteristics of the subjects are presented in Table 1. The inclusion criteria were as follows: (1) the subjects regularly trained for at least 1 day per week; (2) they were healthy and reported no cardiorespiratory and musculoskeletal disorders; and (3) they had completed a marathon $(42.195 \mathrm{~km})$ at least once. Before participation, the subjects were provided with information sheets regarding the study process, and they provided written informed consent. The study was approved by the Ethics Committee of the University of Tsukuba and was performed in accordance with the principles of the Declaration of Helsinki.

\subsection{Treadmill running test}

The treadmill running test was performed on a motorized treadmill (ORK-7000, Ohtake Root Kogyo, Japan) set at $1 \%$ gradient, which accurately reflects the energy cost of outdoor running (Jones and Doust, 1996). The subjects consumed a light meal at least $3 \mathrm{~h}$ before the test, and during the $3 \mathrm{~h}$ prior to the test, only ad libitum water intake was allowed. Body weight was measured before the test (TBF-102, Tanita, Japan).

The subjects completed a two-part test that consisted of an RE test and a maximal incremental test. Expired gas analysis was continuously performed on a breath-by-breath basis using the computerized standard open circuit technique, and the data were then converted into 20-s time-binned mean values (AE-310s, Minato Medical Science, Japan). Before each test, the oxygen and carbon dioxide analyzers were calibrated using known gas concentrations, and flow calibration was performed using a 2-L 
Table 1 Descriptive data of the subjects.

\begin{tabular}{ccccc}
\hline & $\begin{array}{c}\text { Fair } \\
(\mathrm{n}=18)\end{array}$ & $\begin{array}{c}\text { Good } \\
(\mathrm{n}=9)\end{array}$ & $\begin{array}{c}\text { Excellent } \\
(\mathrm{n}=12)\end{array}$ & $\begin{array}{c}\text { All } \\
(\mathrm{n}=39)\end{array}$ \\
\hline Sex (M/W) & $7 / 11$ & $6 / 3$ & $11 / 1$ & $24 / 15$ \\
Age (years) & $40.9 \pm 11.7$ & $40.3 \pm 8.0$ & $31.8 \pm 11.4$ & $38.0 \pm 11.4$ \\
& $(35.5-46.3)$ & $(35.1-45.6)$ & $(25.4-38.3)$ & $(34.4-41.5)$ \\
Height (cm) & $163 \pm 8$ & $169 \pm 8$ & $170 \pm 5^{\mathrm{a}}$ & $166 \pm 8$ \\
& $(159-166)$ & $(164-174)$ & $(167-173)$ & $(164-169)$ \\
Weight (kg) & $55.7 \pm 7.8$ & $57.1 \pm 5.9$ & $59.1 \pm 6.9$ & $57.1 \pm 7.1$ \\
& $(52.1-59.3)$ & $(53.2-60.9)$ & $(55.3-63.0)$ & $(54.8-59.3)$ \\
Training volume (h/week) & $4.0 \pm 1.6$ & $8.5 \pm 5.3^{\mathrm{a}}$ & $5.5 \pm 2.6$ & $5.5 \pm 3.5$ \\
& $(3.2-4.7)$ & $(5.1-11.9)$ & $(4.0-7.0)$ & $(4.4-6.6)$ \\
Training frequency (times/week) & $3.2 \pm 1.1$ & $4.7 \pm 1.4^{\mathrm{a}}$ & $4.5 \pm 1.4^{\mathrm{a}}$ & $3.9 \pm 1.4$ \\
Longest training session (km) & $(2.7-3.7)$ & $(3.7-5.6)$ & $(3.7-5.3)$ & $(3.5-4.4)$ \\
Recent marathon time (min) & $30.2 \pm 15.6$ & $69.3 \pm 42.8^{\mathrm{a}}$ & $58.8 \pm 49.3$ & $48.0 \pm 38.7$ \\
& $(23.0-37.4)$ & $(41.3-97.3)$ & $(30.8-86.7)$ & $(35.9-60.2)$ \\
& $256.7 \pm 30.7$ & $201.8 \pm 12.9^{\mathrm{a}}$ & $176.3 \pm 19.3^{\mathrm{a}}$ & $219.3 \pm 43.4$ \\
& $(242.6-270.9)$ & $(193.4-210.2)$ & $(165.3-187.2)$ & $(205.7-232.9)$ \\
\hline
\end{tabular}

Values are expressed as mean \pm SD and $95 \%$ CI.

a Significantly different from the fair group.

syringe.

The subjects underwent a 5-min RE test at a submaximal intensity. The previous study revealed that $\mathrm{O}_{2}$ cost did not differ from $85 \%$ to $110 \%$ of the average velocity of the best marathon (di Prampero et al., 2009). Therefore, the treadmill velocity was set to $85 \%$, corresponding to the average velocity of a recent marathon. However, as the $\mathrm{O}_{2}$ cost of walking and running are equal at a velocity of approximately $8.0 \mathrm{~km} / \mathrm{h}$; at a velocity lower than this, walking is more efficient (Hagberg and Coyle, 1984). The treadmill velocity was set at $8.0 \mathrm{~km} / \mathrm{h}$ if the runner's recent marathon time was $270 \mathrm{~min}$ or more. Because there was no significant increase in $\dot{\mathrm{V}}_{2}$ during the last 2 min of the RE test, the data obtained from gas analysis during the last $1 \mathrm{~min}$ were used in the analysis. In the RE test, the respiratory exchange ratio (RER) of all the subjects were $<1.0$, and $\mathrm{RE}$ was expressed as the $\mathrm{O}_{2}$ cost $(\mathrm{ml} / \mathrm{kg} / \mathrm{km})$.

Following a 5-min recovery period after the RE test, the maximal incremental test was performed to determine $\% \dot{\mathrm{VO}}_{2} \max$ at $\mathrm{AT}$, vAT, and $\dot{\mathrm{VO}}_{2} \max$. The initial velocity was set at $8.4 \mathrm{~km} / \mathrm{h}$ and was increased by $0.6 \mathrm{~km} / \mathrm{h}$ every $60 \mathrm{~s}$ until volitional exhaustion, which was defined as the point at which the subject could no longer run at the required velocity. AT was defined as the point at which RER stabilized above 1.0 (RER1.0) (Solberg et al., 2005). $\dot{\mathrm{VO}}_{2}$ max was defined as the attainment of at least 2 of the following 4 criteria: (1) a leveling-off of $\dot{\mathrm{V}} \mathrm{O}_{2}$ despite an increase in treadmill velocity, (2) maximal RER $\geq 1.1$, (3) maximal heart rate $\geq 90 \%$ of the subject's age-predicted maximal heart rate (i.e., $220-$ age), and (4) perceived exertion rating $\geq 19$ (Howley et al., 1995).

\subsection{Training status}

Before the treadmill running test, the subjects were asked to complete the questionnaires regarding the training volume, training frequency, and longest training session during the previous 3 months.

\subsection{Statistical analysis}

Data are expressed as mean and standard deviation (SD), with 95\% confidence interval (CI). Statistical analyses were performed using SPSS Statistics 24 (IBM Japan, Japan). Simultaneous multiple regression analysis was used to explain vAT according to a classic model that included $\dot{\mathrm{V}}_{2}$ $\max , \% \dot{\mathrm{VO}}_{2}$ max at AT, and RE. A Pearson correlation analysis was performed for men, women, and both together. For subjects who completed a marathon within the past year, single regression analysis was performed between vAT and recent marathon times. All the subjects were classified in 3 subgroups based on their vAT using percentile values (fair, percentile $\leq 33$; good, percentile between 33 and 66 ; 
and excellent, percentile >66) (Fernandes-da-Silva et al., 2016). For comparison of the classic physiological variables and training status between subgroups, one-way analysis of variance (ANOVA) and Tukey's post hoc test were performed. An unpaired t-test was performed to compare classic physiological variables and vAT between men and women. The significance level for all the comparisons was set at $\mathrm{p}<0.05$.

\section{Results}

\subsection{Relationship between classic physiological variables, vAT, and recent marathon times}

Multiple regression analysis showed that $94 \%$ of vAT values could be explained by $\dot{\mathrm{V}}_{2} \max , \% \dot{\mathrm{V}} \mathrm{O}_{2}$ $\max$ at AT, and RE $(\mathrm{p}<0.001)$. In addition, all variables were significantly explanatory $\left(\dot{\mathrm{V}}_{2} \max , \mathrm{p}\right.$ $<0.001 ; \% \dot{\mathrm{V}}_{2} \max$ at $\mathrm{AT}, \mathrm{p}<0.001$; and RE, $\mathrm{p}<$ 0.001) (Table 2).

In total, 35 subjects had completed a marathon within the past year (154 \pm 111 days). For these subjects, single regression analysis was performed, which showed that $67 \%$ of recent marathon times was explained by vAT $(r=0.82, p<0.001)$.

\subsection{Classic physiological variables and vAT among subgroups}

Age and weight were not significantly different among the subgroups (Table 1). Height was in the excellent group was higher than that in the fair group.

Table 3 shows $\dot{\mathrm{V}}_{2} \max , \% \dot{\mathrm{VO}}_{2} \max$ at $\mathrm{AT}, \mathrm{RE}$,

Table 2 Simultaneous multiple regression with velocity at anaerobic threshold as classic physiological variables.

\begin{tabular}{lrrr}
\hline & \multicolumn{1}{c}{$\mathrm{B}$} & SEE & \multicolumn{1}{c}{$\beta$} \\
\hline (Constant) & 2.643 & 2.160 & \\
$\dot{\mathrm{V}}_{2} \max$ & 0.202 & 0.011 & $0.827^{*}$ \\
$\% \dot{\mathrm{VO}}_{2} \max$ at AT & 0.078 & 0.015 & $0.225^{*}$ \\
$\mathrm{RE}$ & -0.031 & 0.005 & $-0.309^{*}$ \\
\hline $\mathrm{SEE}$ & 0.539 & & \\
$\mathrm{R}^{2}$ & 0.937 & & \\
\hline
\end{tabular}

$\overline{\mathrm{V}} \mathrm{O}_{2} \max$, maximal oxygen uptake; $\% \dot{\mathrm{V}} \mathrm{O}_{2}$ max at AT, fractional utilization of $\dot{\mathrm{V}} \mathrm{O}_{2}$ max at anaerobic threshold; RE, running economy (expressed as oxygen cost); $\mathrm{B}$, unstandardized regression coefficient; SEE, standard error of measurement; $\beta$, regression coefficient; $\mathrm{R}^{2}$, coefficient of determination; ${ }^{*} \mathrm{p}<0.001$ and vAT among the subgroups. One-way ANOVA demonstrated overall significant subgroup differences in $\dot{\mathrm{V}}_{2}$ max RE, and vAT. Tukey's post hoc test demonstrated a stair-step pattern in $\mathrm{V}_{2}$ max (fair $<$ good $<$ excellent). $\mathrm{O}_{2}$ cost in the excellent group was better (i.e., lower) than that in the fair group. \% $\dot{\mathrm{VO}}_{2} \max$ at $\mathrm{AT}$ showed no significant differences among the subgroups. As expected, vAT showed a stair-step pattern among the subgroups.

\subsection{Training status among subgroups}

Table 1 shows the training volume, training frequency, and longest training session for each subgroup. Training volume, training frequency, and longest training session in the good group was higher than those in fair group. Moreover, training frequency between fair and excellent groups was also significantly different. There were no differences between the good and excellent groups in terms of training status.

Recent marathon time in the fair group was significantly lower than that in the good and excellent groups (Table 1). Although recent marathon time between good and excellent groups was not significantly different, the value approached significance $(\mathrm{p}=0.058)$.

\subsection{Classic physiological variables and vAT be- tween men and women}

Table 4 shows classic physiological variables and

Table 3 Comparison of classic physiological variables and velocity at anaerobic threshold among subgroups.

\begin{tabular}{cccc}
\hline & \multicolumn{1}{c}{$\begin{array}{c}\text { Fair } \\
(\mathrm{n}=18)\end{array}$} & $\begin{array}{c}\text { Good } \\
(\mathrm{n}=9)\end{array}$ & $\begin{array}{c}\text { Excellent } \\
(\mathrm{n}=12)\end{array}$ \\
\hline$\dot{\mathrm{V}} \mathrm{O}_{2} \mathrm{max}$ & $49.4 \pm 5.0$ & $58.0 \pm 5.1^{\mathrm{b}}$ & $64.5 \pm 5.6^{\mathrm{a}}$ \\
$(\mathrm{ml} / \mathrm{kg} / \mathrm{min})$ & $(47.1-51.7)$ & $(54.7-61.4)$ & $(61.3-67.7)$ \\
$\% \dot{\mathrm{VO}}{ }_{2} \mathrm{max}$ at $\mathrm{AT}$ & $91.6 \pm 3.5$ & $89.4 \pm 5.1$ & $88.5 \pm 4.3$ \\
$(\%)$ & $(85.8-92.6)$ & $(86.1-92.8)$ & $(86.1-91.0)$ \\
$\mathrm{RE}(\mathrm{ml} / \mathrm{kg} / \mathrm{km})$ & $234.3 \pm 21.5$ & $218.3 \pm 18.5$ & $210.0 \pm 10.0^{\mathrm{b}}$ \\
& $(224.4-244.3)$ & $(206.2-230.4)$ & $(204.3-215.6)$ \\
$\mathrm{vAT}(\mathrm{km} / \mathrm{h})$ & $12.4 \pm 1.2$ & $14.4 \pm 0.0^{\mathrm{b}}$ & $16.4 \pm 1.4^{\mathrm{a}}$ \\
& $(11.9-13.0)$ & $(14.4-14.4)$ & $(15.6-17.2)$ \\
\hline
\end{tabular}

$\dot{\mathrm{V}} \mathrm{O}_{2} \mathrm{max}=$ maximal oxygen uptake; $\% \dot{\mathrm{VO}}_{2} \mathrm{max}$ at $\mathrm{AT}$, fractional utilization of $\mathrm{V}_{2}$ max at anaerobic threshold; RE, running economy (expressed as oxygen cost); vAT, velocity at anaerobic threshold. Values are expressed as mean \pm SD and $95 \% \mathrm{CI}$.

a Significantly different $(\mathrm{p}<0.05)$ from fair and good groups.

${ }^{b}$ Significantly different $(p<0.05)$ from the fair group. 


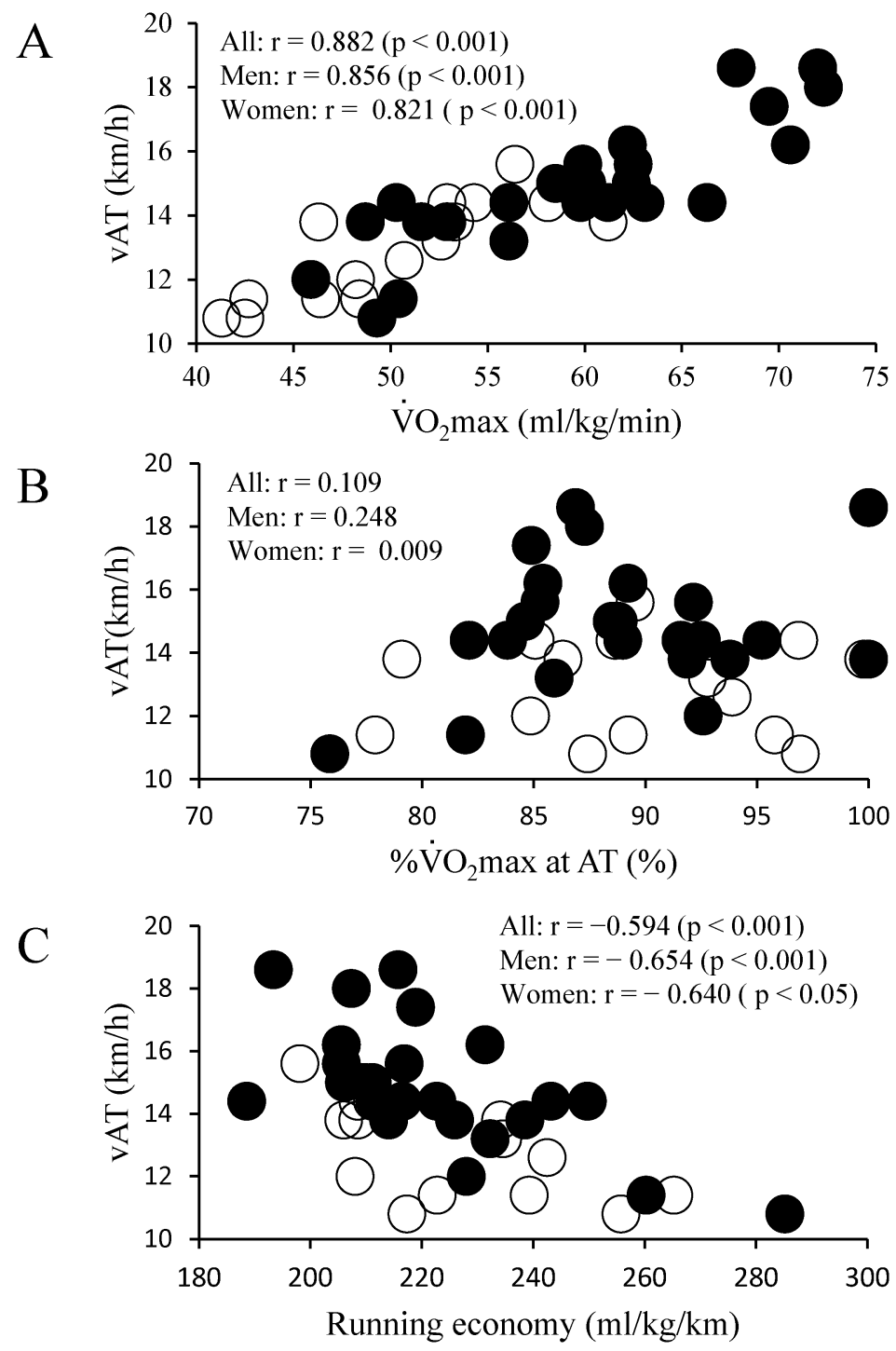

Figure 1 Relationship between maximal oxygen uptake (A), fractional utilization of maximal oxygen uptake at anaerobic threshold (B), and running economy (C) and velocity at anaerobic threshold.

Closed circles indicate men and open circles indicate women.

Table 4 Comparison of classic physiological variables and velocity at anaerobic threshold between men and women.

\begin{tabular}{cccc}
\hline & $\begin{array}{c}\text { Men } \\
(\mathrm{n}=24)\end{array}$ & $\begin{array}{c}\text { Women } \\
(\mathrm{n}=15)\end{array}$ & $\begin{array}{c}\text { All } \\
(\mathrm{n}=39)\end{array}$ \\
\hline$\dot{\mathrm{V}} \mathrm{O}_{2} \mathrm{max}$ & $59.6 \pm 7.8$ & $50.4 \pm 5.9^{\mathrm{a}}$ & $56.0 \pm 8.4$ \\
$(\mathrm{ml} / \mathrm{kg} / \mathrm{min})$ & $(56.4-62.7)$ & $(47.4-53.4)$ & $(53.4-58.7)$ \\
$\% \dot{\mathrm{VO}}_{2} \mathrm{max}$ at AT & $88.7 \pm 5.6$ & $89.6 \pm 6.5$ & $89.1 \pm 5.9$ \\
$(\%)$ & $(86.5-91.0)$ & $(86.3-92.9)$ & $(87.2-90.9)$ \\
$\mathrm{RE}(\mathrm{ml} / \mathrm{kg} / \mathrm{km})$ & $222.4 \pm 21.5$ & $224.3 \pm 19.9$ & $223.1 \pm 20.7$ \\
& $(213.8-231.0)$ & $(214.2-234.4)$ & $(216.6-229.6)$ \\
$\mathrm{vAT}(\mathrm{km} / \mathrm{h})$ & $14.9 \pm 2.0$ & $12.9 \pm 1.5^{\mathrm{a}}$ & $14.1 \pm 2.1$ \\
& $(14.0-15.7)$ & $(12.1-13.7)$ & $(13.5-14.8)$ \\
\hline
\end{tabular}

$\dot{\mathrm{V}} \mathrm{O}_{2} \max =$ maximal oxygen uptake; $\% \dot{\mathrm{VO}}_{2} \max$ at $\mathrm{AT}$, fractional utilization of $\dot{\mathrm{V}}_{2}$ max at anaerobic threshold; RE, running economy (expressed as oxygen cost); vAT, velocity at anaerobic threshold. Values are expressed as mean \pm SD and $95 \%$ CI.

a Significantly different $(p<0.05)$ from men.
vAT between men and women. $\dot{\mathrm{V}} \mathrm{O}_{2} \max$ and vAT in men were significantly higher than that in women. $\% \dot{\mathrm{V}}_{2} \max$ at $\mathrm{AT}$ and $\mathrm{RE}$ were not significantly different between men and women.

Figure 1 shows the relationship between classic physiological variables and vAT. The significant relationships of $\dot{\mathrm{V}}_{2}$ max and $\mathrm{RE}$ were unchanged between men and women.

\section{Discussion}

The present study investigated the relationship between classic physiological variables and performance in recreational runners. The main finding of our study was that $\dot{\mathrm{V}}_{2} \max , \% \dot{\mathrm{V}}_{2}$ max at $\mathrm{AT}$, and 
RE can precisely explain vAT, which is highly correlated with recent marathon times. This finding indicates that $\mathrm{VAT}$ is a representative performance index reflecting classic physiological variables.

Measuring functional capacity during a treadmill test has the advantage of evaluating performance without being affected by the environmental factors. Furthermore, a time lag existed between treadmill running test and recent marathon race in the present study ( $n=35,154 \pm 111$ days), suggesting that the classic physiological variables may change somewhat from those in the race. Takayama et al. (2017) showed that approximately $80 \%$ of recent marathon time could be explained using vAT $(r=0.897, \mathrm{p}<$ 0.001 ) in 11 recreational runners who completed the same race one week before the test. Compared with that previous report, the explanatory rate in this study was relatively lower (67\%). The vAT was used as performance index, because we wanted to focus on physiological aspects.

$\dot{\mathrm{V}} \mathrm{O}_{2} \mathrm{max}$ is limited by the capacity of the cardiorespiratory system to deliver $\mathrm{O}_{2}$ to the exercising muscles (Bassett and Howley, 2000). In the present study, $\dot{\mathrm{V}} \mathrm{O}_{2}$ max showed a stair-step pattern among the subgroups (fair < good < excellent). Moreover, the highest correlation coefficient value was observed between $\dot{\mathrm{VO}}_{2}$ max and vAT $(\mathrm{r}=0.882)$. It is well established that a high $\dot{\mathrm{V}}_{2}$ max is a prerequisite for success in distance running performance (Foster, 1983; Hagan et al., 1981; Sjödin and Svedenhag, 1985). For example, Foster (1983) has investigated the relationship between $\dot{\mathrm{V}}_{2}$ max and marathon time in 25 well-trained male runners and has reported that the marathon time was highly correlated with $\dot{\mathrm{V}}_{2} \max (\mathrm{r}=-0.96)$. The data collected in the present study support these previous findings.

Morgan et al. (1995) investigated the $\mathrm{O}_{2}$ cost in 4 subgroups at different levels (elite, subelite, good, and untrained runners) and showed that untrained runners were uneconomical than other runners, whereas, subelite and good runners were uneconomical than elite runners. They also showed that the average within-group variability in the $\mathrm{O}_{2}$ cost was similar across categories and that a marked overlap of minimum, mean, and maximal economy values existed across groups. In the present study, the excellent group was more economical than the fair group. In addition, 95\% CI values of the $\mathrm{O}_{2}$ cost overlapped between the excellent and good groups
(Table 3). These results are in agreement with those reported by Morgan et al. (1995). In the past, RE in recreational runners had not been considered as an important physiological factor for determining distance running performance (Engeroff et al., 2016). However, a recent study has provided evidence that $\mathrm{RE}$ influences distance running performance even in recreational runners (Engeroff et al., 2016). Taken together, we would like to emphasize that recreational runners should pay attention not only to $\mathrm{V}_{2}$ max but also to improvement in RE (i.e., reduction of $\mathrm{O}_{2}$ cost).

$\% \dot{\mathrm{V}}_{2}$ max at $\mathrm{AT}$ showed no significant subgroup differences. Moreover, the lowest correlation coefficient value was observed between $\% \dot{\mathrm{V}} \mathrm{O}_{2} \max$ at AT and vAT (Figure 1). It has been reported by several investigators that the $\% \dot{\mathrm{V}}_{2}$ max has a minor impact on eudurance performance compared with $\dot{\mathrm{V}} \mathrm{O}_{2} \max$ and RE (McLaughlin et al., 2010; Storen et al., 2013). Londeree and Ames (1975) have reported $\% \dot{\mathrm{V}} \mathrm{O}_{2}$ max at MLSS in subjects with different states of conditioning, considering the frequency, quantity, and quality of conditioning during the previous 6 months and have shown that $\% \dot{\mathrm{V}} \mathrm{O}_{2}$ max at MLSS highly correlates with conditioning $(r=0.82)$. Despite the significant difference in the training status of the subgroups in this study, all the groups were well trained. Taken together, it may be assumed that the absence of differences in $\% \dot{\mathrm{VO}}_{2} \max$ at AT among subgroups is attributable to the condition of the runners in this study. Furthermore, previous and present results lead us to presume that $\% \dot{\mathrm{VO}}_{2}$ max at $\mathrm{AT}$ is an aerobic conditioning marker rather than a performance determining factor.

This study included male and female recreational runners. It is well established that $\dot{\mathrm{V}} \mathrm{O}_{2} \mathrm{max}$ in women is lower than that in men because of higher body fat and lower red cell mass for a given body weight (Joyner, 2017). However, there seems to be no sex difference in relationship between classic physiological variables and performance (Joyner, 1993, 2017). In fact, the significant relationship between $\dot{\mathrm{VO}}_{2} \max$ (men: $\mathrm{r}=0.856$, women: $\mathrm{r}=0.821$ ) and RE (men: $r=-0.654$, women: $r=-0.640$ ) and vAT was unchanged between men and women (Figure 1). Thus, we believe that the mixed-sex subjects did not affect the results of this study. 


\section{Conclusions}

The present study indicated that during a treadmill running test, $\dot{\mathrm{V}}_{2} \max , \% \dot{\mathrm{V}} \mathrm{O}_{2}$ max at $\mathrm{AT}$, and $\mathrm{RE}$ can precisely explain $\mathrm{vAT}$, which is highly correlated with recent marathon times.

\section{References}

Barnes, K. R. and Kilding, A. E. (2015). Running economy: measurement, norms, and determining factors. Sports Med. Open, 1: 9.

Bassett, D. R., Jr. and Howley, E. T. (2000). Limiting factors for maximum oxygen uptake and determinants of endurance performance. Med. Sci. Sports Exerc., 32: 70-84.

Chin, C., Kazmucha, J., Kim, N., Suryani, R., and Olson, I. (2010). VO2@RER1.0: a novel submaximal cardiopulmonary exercise Index. Pediatr. Cardiol., 81: 50-55.

di Prampero, P. E., Salvadego, D., Fusi, S., and Grassi, B. (2009). A simple method for assessing the energy cost of running during incremental tests. J. Appl. Physiol., 107: 1068-1075.

Engeroff, T., Bernardi, A., Vogt, L., and Banzer, W. (2016). Running economy assessment within cardiopulmonary exercise testing for recreational runners. J. Sports Med. Phys. Fitness, 56: 200-205.

Farrell, P. A., Wilmore, J. H., Coyle, E. F., Billing, J. E., and Costill, D. L. (1979). Plasma lactate accumulation and distance running performance. Med. Sci. Sports, 11: 338-344.

Fernandes-da-Silva, J., Castangna, C., Teixeira, A. S., Carminatti, L. J., and Guglielmo, L. G. (2016). The peak velocity derived from the Carminatti Test is related to physical match performance in young soccer players. J. Sports Sci., 34: 2238-2245.

Foster, C. (1983). VO2max and training indices as determinants of competitive running performance. J. Sports Sci., 1: 13-22.

García-Pinillos, F., Soto-Hermoso, V. M., and LatorreRomán, P. A. (2017). How does high-intensity intermittent training affect recreational endurance runners? Acute and chronic adaptations: a systematic review. J. Sport Health Sci., 6: 54-67.

Hagan., R. D., Smith, M. G., and Gettman, L. R. (1981). Marathon performance in relation to maximal aerobic power and training indicies. Med. Sci. Sports Exerc., 13: 185-189.

Hagberg, J. M. and Coyle, E. F. (1984). Physiologic comparison of competitive racewalking and running. Int. J. Sports Med., 5: 74-77.

Howley, E. T., Bassett, D. R. Jr., and Welch, H. G. (1995). Criteria for maximal oxygen uptake: review and commentary. Med. Sci. Sports Exerc., 27: 1292-1301.

Jones, A. M. and Carter, H. (2000). The effect of endurance training on parameters of aerobic fitness. Sports Med., 29: 373-386.

Jones, A. M. and Doust, J. H. (1996). A 1\% treadmill grade most accurately reflects the energetic cost of outdoor running. J. Sports Sci., 14: 321-327.

Joyner, M. J. (1991). Modeling: optimal marathon performance on the basis of physiological factors. J. Appl. Physiol., 70: 683-687.

Joyner, M. J. (1993). Physiological limiting factors and distance running: influence of gender and age on record performances. Exerc. Sports Sci. Rev., 21: 103-134.
Joyner, M. J. (2017). Physiological limits to endurance exercise performance: influence of sex. J. Physiol., 595: 2949-2954.

Joyner, M. J. and Coyle, E. F. (2008). Endurance exercise performance: the physiology of champions. J. Physiol., 586: $35-44$.

Laplaud, D. and Menier, R. (2003). Reproducibility of the instant of equality of pulmonary gas exchange and its physiological significance. J. Sports Med. Phys. Fitness, 43: 437-443.

Leti, T., Mendelson, M., Laplaud, D., and Flore, P. (2012). Prediction of maximal lactate state in runners with an incremental test on the field. J. Sports Sci., 30: 609-616.

Londeree, B. R. and Ames, S. A. (1975). Maximal steady state versus state of conditioning. Eur. J. Appl. Physiol. Occup. Physiol., 34: 267-278.

McLaughlin, J. E., Howley, E. T., Bassett, D. R. Jr., Thompson, D. L., and Fitzhungh, E. C. (2010). Test of the classic model for predicting endurance running performance. Med. Sci. Sports Exerc., 42: 991-997.

Morgan, D. W., Bransford, D. R., Costill, D. L., Daniels, J. T., Howley, E. T., and Krahenbuhl, G. S. (1995). Variation in the aerobic demand of running among trained and untrained subjects. Med. Sci. Sports Exerc., 27: 404-409.

Noakes, T. D., Myburgh, K. H., and Schall, R. (1990). Peak treadmill running velocity during the VO2max test predicts running performance. J. Sports Sci., 8: 35-45.

Rhodes, E. C. and McKenzie, D. C. (1984). Predicting marathon time from anaerobic threshold measurements. Physi. Sportsmed., 12: 95-98.

Roecker, K., Schotte, O., Niess, A. M., Horstmann, T., and Dickhuth, H. H. (1998). Predicting competition performance in long-distance running by means of a treadmill test. Med. Sci. Sports Exerc., 30: 1552-1557.

Sjödin, B. and Jacobs, I. (1981). Onset of blood lactate accumulation and marathon running performance. Int. J. Sports Med., 2: 23-26.

Sjödin, B. and Svedenhag, J. (1985). Applied physiology of marathon running. Sports Med., 2: 83-89.

Solberg, G., Robstad, B., Skjønsberg, O. H., and Borchsenius, F. (2005). Respiratory gas exchange indices for estimating the anaerobic threshold. J. Sports Sci. Med., 4: 29-36.

Støren, Ø., Ulevåg, K., Larsen, M. H., Støa, E. M., and Helgerud, J. (2013). Physiological determinants of the cycling time trial. J. Strength Cond. Res., 27: 2366-2373.

Takayama, F., Aoyagi, A., Shimazu, W., and Nabekura, Y. (2017). Effects of marathon running on aerobic fitness and performance in recreational runners one week after a race. $\mathrm{J}$. Sports Med., 2017: 9402386.

Tjelta, L. I., Tjelta, A. R., and Dyrstadm, S. M. (2012). Relationship between velocity at anaerobic threshold and factors affecting velocity at anaerobic threshold in elite distance runners. Int. J. Appl. Sports Sci., 24: 8-17. 


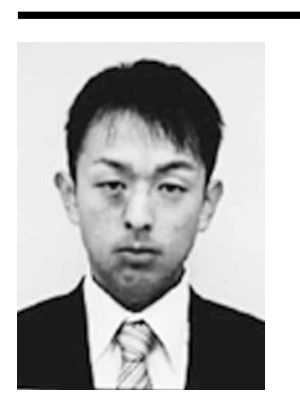

Name:

Fuminori Takayama

\section{Affiliation:}

Faculty of Health and Sport Sciences, University of Tsukuba

Research Fellow of Japan Society for the Promotion of Science

Address:

1-1-1 Tennodai, Tsukuba-shi, Ibaraki 305-8574, Japan

Brief Biographical History:

Fuminori Takayama is the research fellowship for young scientists of Japan society for the promotion of Science. He obtained Ph.D. at University of Tsukuba in 2018.

Main work:

-Takayama, F., Aoyagi, A., Shimazu, W., and Nabekura, Y. (2017). Effects of marathon running on aerobic fitness and performance in recreational runners one week after a race. J. Sports Med., 2017: 9402386.

Membership in learned Societies:

-Japan Society of Physical Education, Health and Sport Sciences

- Japanese Society of Physical Fitness and Sports Medicine

-Society for Running 